\title{
Recognition of Negative Mesoscale Factors for Severe-Weather Potential: A Case Study
}

\author{
Charles A. Doswell III* \\ NOAA/OAR/National Severe Storms Laboratory, Norman, Oklahoma \\ DONALD V. BAKER \\ NOAA/NWS Weather Forecast Office, Lubbock, Texas \\ Charlie A. LiLES \\ NOAA/NWS Weather Forecast Office, Albuquerque, New Mexico
}

(Manuscript received 2 November 2001, in final form 23 April 2002)

\begin{abstract}
The case of 7-8 June 1998 in eastern New Mexico and western Texas is used to illustrate the challenge of recognizing possible negative effects created by mesoscale processes. In this case, a region of cloud-covered cool air (which was associated with early thunderstorms) may have limited the tornadic potential of severe convection. Although the tornado potential in the synoptic situation was not highly portentous, supercell storms did eventually form, one of which was persistent for many hours. There were only relatively brief and weak tornadoes reported from this storm early in its life, despite its persistence as a long-lived supercell that produced a long swath of large hail. In this case, the development of thunderstorms east of the threat area early in the day maintained cloudiness that apparently inhibited the destabilization of the surface-based air mass over which the afternoon thunderstorms eventually moved. The persistent supercell formed on the dryline but overrode this mesoscale cool air mass relatively soon after it developed. It was able to persist as an elevated supercell despite the relatively stable near-surface air mass, but its tornadic production may have been limited by its interaction with this mesoscale feature. Implications for operational forecasting and warnings are discussed.
\end{abstract}

\section{Introduction}

Possibly one of the greatest challenges facing weather forecasters is the recognition of reduced potential for hazardous weather. This seemingly paradoxical situation arises partly because severe thunderstorms are a relatively rare event in any one place, even in the regions in which such storms are most common. Thus, by far the majority of forecast days are associated with "nonevents" rather than events. However, it is also the case that in parts of the United States, notably the southern plains region (including eastern New Mexico, Texas, and Oklahoma), there are many days during the storm season when the possibility of severe thunderstorms with tornadoes is not negligible. The challenge to forecasters is to be able to recognize those few days when

\footnotetext{
* Current affiliation: Cooperative Institute for Mesoscale Meteorological Studies, University of Oklahoma, Norman, Oklahoma.

Corresponding author address: Dr. Charles A. Doswell III, CIMMS, Sarkey's Energy Center, The University of Oklahoma, Room 1110, 100 East Boyd St., Norman, OK 73019.

E-mail: cdoswell@hoth.gcn.ou.edu
}

the potential is going to be realized, versus the majority of days, when it is not. Most of the literature on severe storms and tornadoes necessarily focuses on events, not nonevents, whereas forecasters necessarily have the most experience with days on which the situation fails to produce a major weather-related disaster.

Even though a nonnegligible possibility of a tornado is present on many days in the southern plains, there is much evidence that mesoscale (and even storm-scale) processes have a major impact on the extent to which that tornado potential will be realized. When considering the role of mesoscale processes related to some severe-weather event, most studies have focused on how mesoscale processes contribute to an enhancement of the severe-weather potential. There can be no doubt that such enhancements occur (e.g., Magor 1959; Doswell 1987; Rockwood and Maddox 1988; Rasmussen et al. 2000), but this is not a complete picture of the role played by mesoscale processes. In fact, within our experience, the most common impact of mesoscale events is to reduce the chances for severe convection.

Therefore, in the following study, a case example is used to illustrate the apparently negative effects associated with mesoscale processes on the tornado potential 
of subsequent deep moist convection. A major challenge we confront in this work, is that it unfortunately is not possible to know what would have happened had the mesoscale processes not been operating. This issue is what makes the study of nonevents particularly challenging. Because we cannot know what might have happened on the day of our case in the absence of certain mesoscale events, the best we can do is to show that the observations are at least consistent with the hypothesis that tornado potential was reduced by these mesoscale processes.

Experienced forecasters know that when convective outflows reach mesoscale proportions, they often act to inhibit further deep, moist convective storms. After all, convective storms act to reduce the convective available potential energy (CAPE) by producing cool, stable outflows. For this particular case, however, the apparent result $^{1}$ of early convection was neither total suppression of convection developing later in the day, nor even the prevention of severe thunderstorm activity, but rather the limitation of the tornado potential. Given that a few brief, weak tornadoes were observed, that tornado potential certainly cannot be considered to be negligible. It is known (Fujita 1960; Agee et al 1976; Forbes 1981) that long-lived supercells are capable of producing a series of tornadoes (sometimes called a tornado family). The strongest tornadoes in such a series are typically not the first ones produced by the storm. Forecaster experience (Jones et al. 1985; Moller et al. 1994; Moller 2001, p. 464) suggests that if a storm produces at least one tornado, then continuing with tornado warnings until that storm dissipates is a plausible strategy.

For forecasters making warning decisions, it is also regrettably the case that many supercells produce only a few brief, weak tornadoes (as in this case), if any at all. Brief, weak tornadoes were observed early in the life cycle of this particular long-lived supercell. Should tornado warnings have been continued for the lifetime of the storm or was it possible to recognize when the tornadic phase was over? Our example illustrates that an operational diagnosis of atmospheric processes, including those at the mesoscale whenever possible, might be helpful in making this decision. A complete diagnosis should include due consideration to those mesoscale aspects of a forecast situation that are unfavorable to a particular event's occurrence.

Regardless of our ability to make a convincing argument about what might have happened with this case under different circumstances, we believe it to be useful to consider the potential negative impacts of mesoscale processes on severe convection, so that forecasters can have some guidance about what to look for in producing the many nonevents they will have to handle in operations. Therefore, section 2 gives a synoptic-scale overview of the situation on the morning of 7 June 1998 in

\footnotetext{
${ }^{1}$ The caveat concerning the difficulty of proving any negative impacts should be considered implicit in all that follows.
}

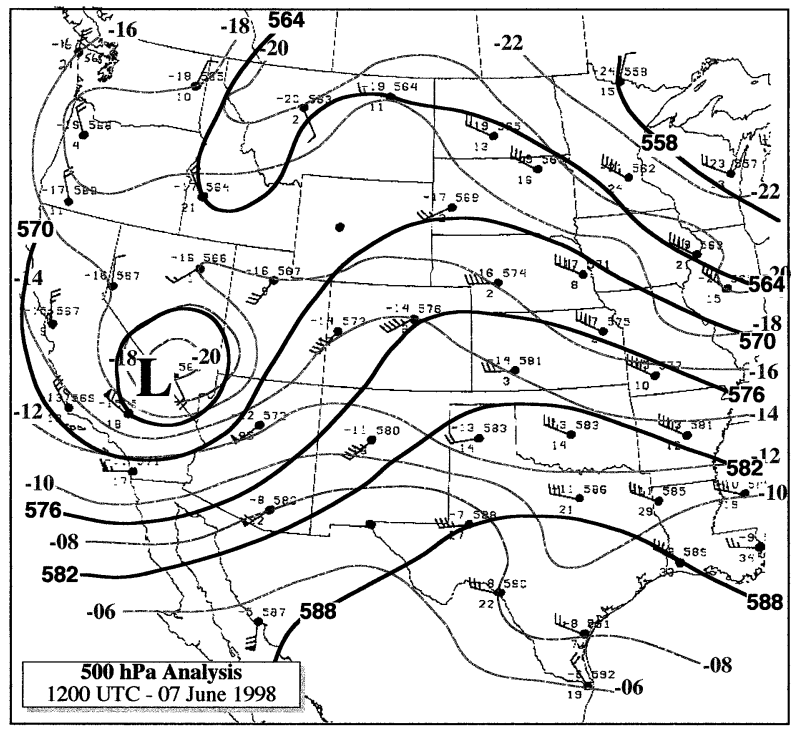

FIG. 1. Analysis of features at $500 \mathrm{hPa}$ at 1200 UTC 7 Jun 1998 , showing isohypses (heavy solid lines, contoured at 6-dam intervals) and isotherms (light gray lines, contoured at $2{ }^{\circ} \mathrm{C}$ intervals). Station plot shows temperature $\left({ }^{\circ} \mathrm{C}\right)$ in the upper left, dewpoint depression $\left({ }^{\circ} \mathrm{C}\right)$ in the lower left, and geopotential height (dam) in the upper right.

eastern New Mexico and western Texas, focusing on the tornado potential implied that morning. Then, in section 3, a detailed surface analysis is combined with satellite imagery and soundings to describe the characteristics of a mesoscale region of clouds and outflow that developed during the day of 7 June. In section 4, a description of convective evolution reveals the apparent influence of the mesoscale processes. Some discussion and conclusions are presented in section 5 .

\section{Synoptic-scale overview}

A look at the 500-hPa analysis at 1200 UTC shows a vigorous short-wave trough in the southwestern United States (Fig. 1). Given the upstream 500-hPa winds in excess of $25 \mathrm{~m} \mathrm{~s}^{-1}$, it was plausible to expect the approaching trough to increase the mid- and upper-tropospheric winds in eastern New Mexico and western Texas during the following afternoon. In the layer from 700 to $500 \mathrm{hPa}$, a region of high lapse rates (implied by the $700-500-\mathrm{hPa}$ temperature difference) was being advected over the plains in the southwesterly flow ahead of the short-wave trough (Fig. 2). Surface flow at this time was still affected by the recent passage of a surface anticyclone, having a large easterly component over Texas but becoming more southerly in northern Oklahoma and the Texas Panhandle (Fig. 3). Surface winds could be expected to increase during the day as surface pressures fell with the approach of the trough aloft. Combined with increasing flow aloft, the surfaceto-500-hPa wind shear could be expected to increase to the point at which supercells would be likely. Although 


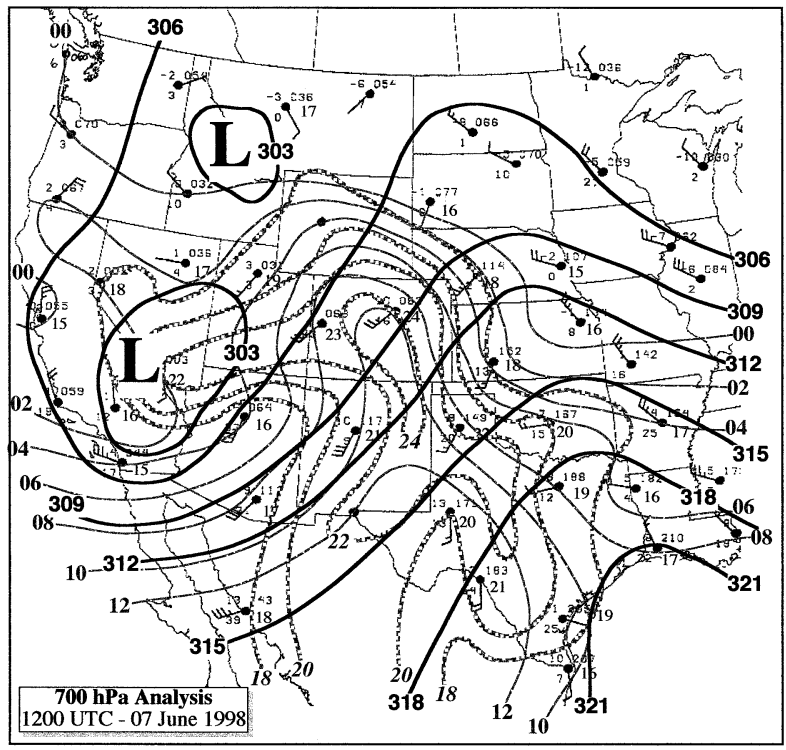

FIG. 2. Analysis of features at $700 \mathrm{hPa}$ at 1200 UTC 7 Jun 1998 showing isohypses (heavy solid lines, contoured at 3-dam intervals), 700-500-hPa temperature difference (heavy gray lines, contoured at $2^{\circ} \mathrm{C}$ intervals, beginning at $18^{\circ} \mathrm{C}$ ), and isotherms (light gray lines, contoured at $2^{\circ} \mathrm{C}$ intervals, beginning at $0^{\circ} \mathrm{C}$ ). Station model is the same as in Fig. 1 except that the $700-500-\mathrm{hPa}$ temperature difference $\left({ }^{\circ} \mathrm{C}\right)$ is plotted in the lower right.

surface dewpoints were not extremely high over the plains for this late in the spring, the setting seemed primed to begin a rapid moisture return.

Yet another input for the field forecaster was the morning outlook for severe thunderstorms from the National Weather Service's Storm Prediction Center SPC). The outlook issued at 1523 UTC said about eastern New Mexico and far western Texas:

The morning raobs show that rich Gulf moisture ... with boundary layer mixing ratios approaching $15 \mathrm{~g} \mathrm{~kg}^{-1} \ldots$ which had been shunted southward into eastern New Mexico during the last $48 \mathrm{~h}$ is now rapidly returning northwestward through the Rio Grande valley into far western Texas and eastern New Mexico. Surface dewpoints in the upper 50s to low 60s should extend as far north as Amarillo/Tucumcari by late afternoon. ${ }^{2}$

That discussion described the synoptic situation in the following terms:

Active pattern over the central and southern Plains this period as upper low and associated speed maximum now over the southern Great Basin shear east-northeastward across the southern/central Rockies. At the surface ... low now over southern Utah should give way to stronger cyclogenesis in the lee of the Colorado Rockies by early

\footnotetext{
${ }^{2}$ Observe that the wording of this outlook may be confusing. The intended meaning is that the boundary layer mixing ratios in eastern New Mexico had been pushed southward earlier and were at that time in the process of returning.
}

this afternoon. The Colorado low should then track eastnortheastward along developing warm front into southern Nebraska later tonight/early Monday.

On this basis, the lead SPC forecaster called for a "slight risk" of severe thunderstorms in the region shown in Fig. 4, which included eastern New Mexico and far western Texas (hereinafter referred to as the "threat area"). Moisture, instability, and shear were expected to increase during the day, increasing the threat of supercells and tornadoes.

In the period following that morning outlook, the threat area continued under the same "slight risk" threat assessment through several updates by the SPC. By 0000 UTC that evening, the synoptic pattern had evolved more or less as forecast. At $500 \mathrm{hPa}$ (Fig. 5), the short-wave trough had moved east-northeastward, displacing the ridge over the area at 1200 UTC and bringing relatively strong (20-25 $\mathrm{m} \mathrm{s}^{-1}$ ) southwesterly winds aloft across the threat area. High midtropospheric lapse rates (as shown by the 700-500-hPa temperature difference field in Fig. 6) had not moved very far eastward, however, with the main axis running slightly west of the Continental Divide through New Mexico and into Colorado. At $850 \mathrm{hPa}$ (Fig. 7), a lee cyclone had indeed developed, with a strong southeasterly current arising over the lower Rio Grande valley and extending into western Kansas, in response to that cyclogenesis.

Surface features in the threat area were complex, with cyclones in Colorado and New Mexico developing in the lee of the Rocky Mountains, apparently in response to the approaching short-wave trough. We will be elaborating on the details of this evolution in section 3 , but a dryline had formed in eastern New Mexico, not far west of the Texas border by this time (Fig. 8). Surface winds increased to $10-15 \mathrm{~m} \mathrm{~s}^{-1}$ from the east-southeast, thereby producing the anticipated surface-to-500-hPa vector wind shears in excess of $30 \mathrm{~m} \mathrm{~s}^{-1}$ (corresponding to an estimated value for $|\Delta \mathbf{V}| / \Delta Z$ within that layer of $7.5 \times 10^{-3} \mathrm{~s}^{-1}$, where $\mathbf{V}$ is the vector wind and $z$ is height), generally considered sufficient for supercells (Weisman and Klemp 1986). Although surface dewpoint values in the southern part of the threat area had increased in the $12 \mathrm{~h}$ since 1200 UTC (cf. Fig. 3), temperatures in western Texas had not increased as much as those in southeastern New Mexico.

At synoptic scales, the situation certainly contained the potential for development of tornadic supercells, even though that potential was well short of that associated with a major outbreak of tornadoes. Simply by looking at the analyzed weather charts for this case, we believe that tornadic supercells had to be considered a credible possibility in the threat area. Even for "synoptically evident" cases (Doswell et al. 1993) that produce tornado outbreaks, however, the actual evolution of events can be strongly dependent on the mesoscale details (e.g., Davies et al. 1994). The data in Fig. 8 


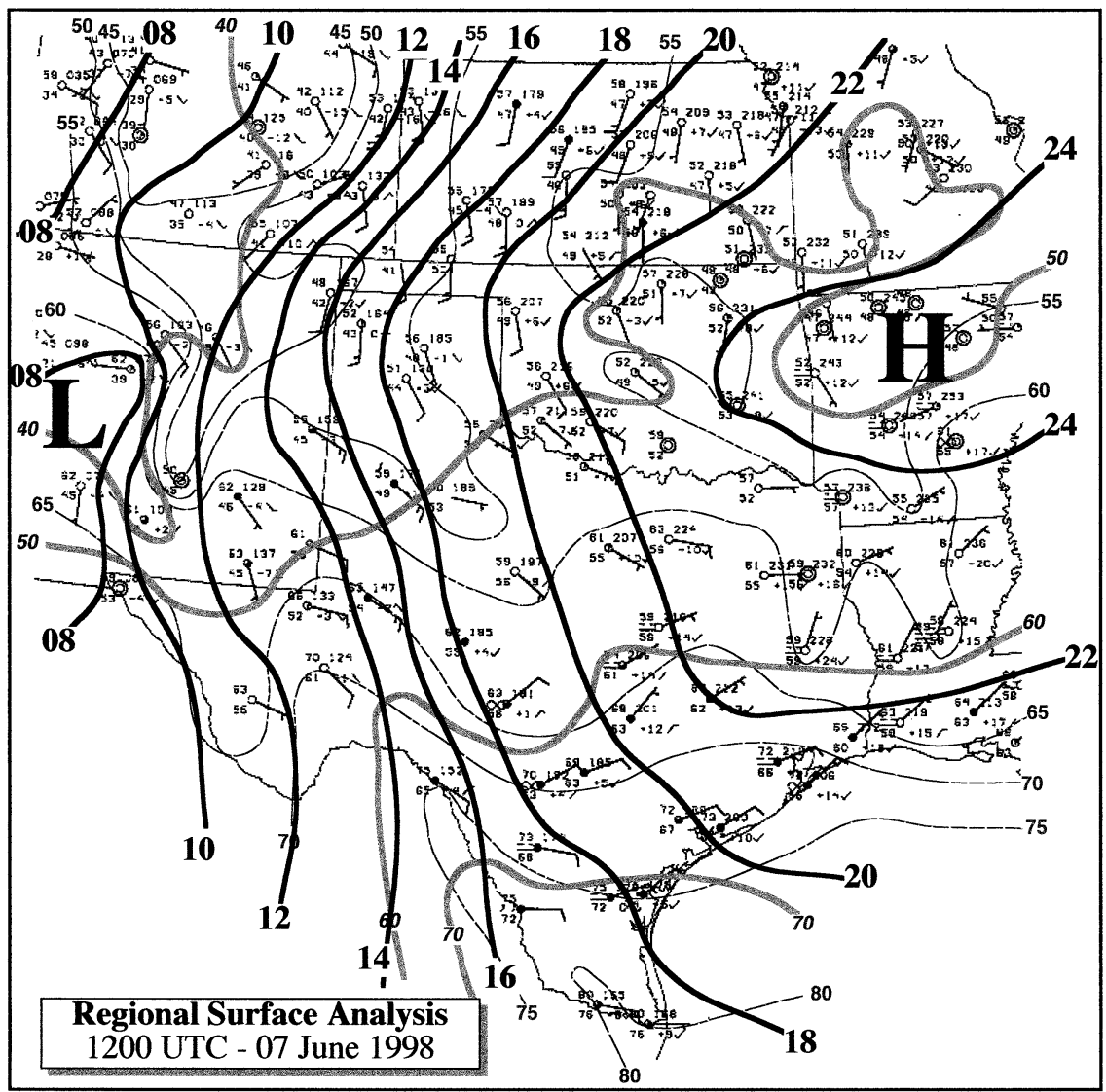

FIG. 3. Regional surface analysis at 1200 UTC 7 Jun 1998, showing isobars (heavy solid lines, contoured at $2-\mathrm{hPa}$ intervals), isotherms (thin gray lines, contoured at $5^{\circ} \mathrm{F}$ intervals), and isodrosotherms (heavy gray lines, contoured at $10^{\circ} \mathrm{F}$ intervals, beginning at $40^{\circ} \mathrm{F}$ ). The station plot model is conventional.

suggest some important mesoscale complexity, so we will consider this in more detail in the next section.

\section{Subsynoptic-scale analysis}

Justifiable "mesoscale" analysis requires a data density that is not always available; hence, we consider this analysis to be "subsynoptic" rather than truly mesoscale. Given that the operational surface observations have an average distance to their nearest neighbor on the order of $100 \mathrm{~km}$, it is possible at least to do a subsynoptic-scale analysis, especially when considering the hour-by-hour changes, to infer the mesoscale structure with some limited confidence. Confidence in the resulting analysis can be substantially improved, however, by combining satellite imagery with the surface data. ${ }^{3}$

Extensive mixed low and high clouds were present over the threat area at 1402 UTC (Fig. 9a), extending

\footnotetext{
${ }^{3}$ In our case, the evolution of the mesoscale thermal boundaries is complex; even 3-h surface analyses are not sufficient to give a clear picture of the evolution. For brevity, we are not showing hourly surface analyses.
}

southeastward to near the Gulf of Mexico. Relatively clear skies prevailed that morning over north Texas, most of Oklahoma, and the eastern Texas Panhandle. By late morning (1702 UTC; Fig. 9b), however, thun-

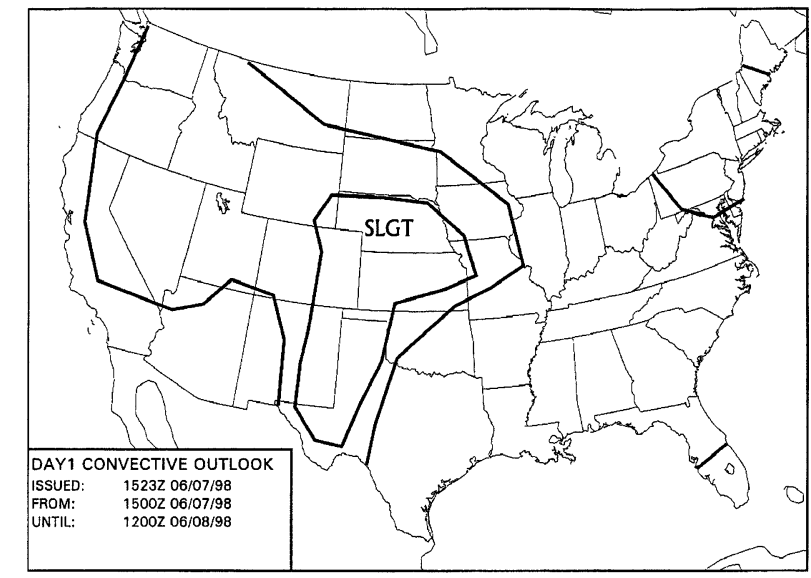

FIG. 4. Map showing the SPC convective outlook product issued at 1523 UTC. 


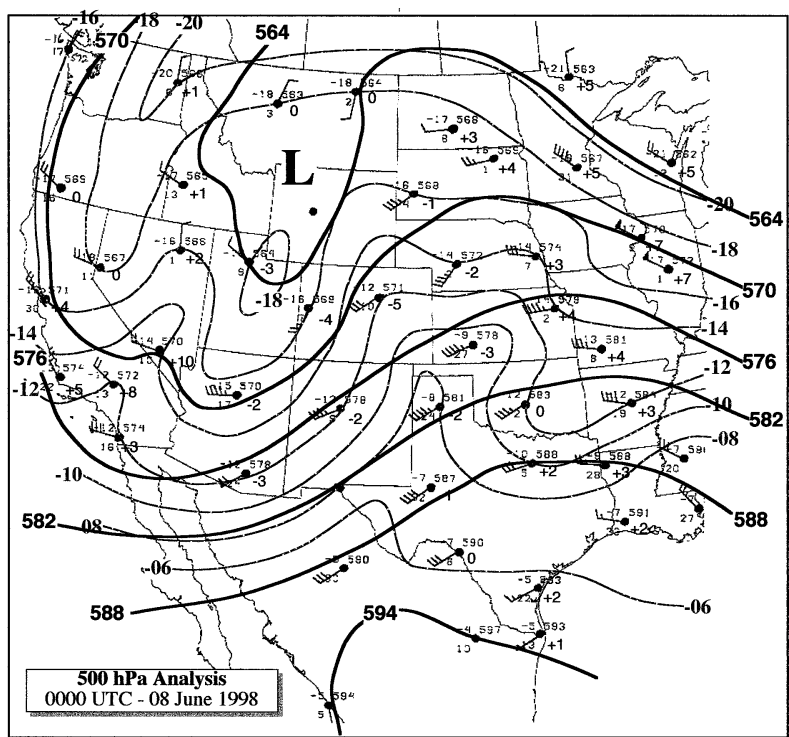

FIG. 5. The 500-hPa analysis as in Fig. 1 but for 0000 UTC 8 Jun 1998; 12-h height changes (dam) have been added to the station model in the lower right.

derstorms developed in far western Texas, from near Midland northward into the western panhandle.

Relatively cool temperatures were centered in the northwestern Texas Panhandle, extending eastward to near the Oklahoma border and southward to south of Lubbock, Texas. As suggested by the surface data at 1800 UTC (Fig. 10), these cool temperatures were likely due to the outflows from the aforementioned thunderstorm activity, which maintained cloudy skies over the affected region. Observe that the storms were developing within relatively cool surface temperatures, with warmer temperatures and higher dewpoints to the south, where skies were clearing and the flow was bringing in more moisture.

Keeping in mind the potential impact of this continued cloudiness, note that by 2115 UTC there were three main foci for thunderstorms: one moving out of the extreme northeastern Texas Panhandle, a second area of thunderstorms along the southeastern portion of the Texas Panhandle, and a third moving into north Texas (Fig. $9 \mathrm{c})$. Considerable cloudiness persisted over most of the far west Texas part of the threat area, but only scattered high and low clouds were present in most of eastern New Mexico. The associated 2100 UTC surface analysis (Fig. 11a) reveals the persistent cool temperatures under the cloud cover in far west Texas. Based on the surface data and the 0000 UTC 500-hPa isotherms, an estimate of the surface parcel-based instability can be developed from the surface equivalent potential temperature $\left(\theta_{e}\right)$ field. There is a unique temperature at $500 \mathrm{hPa}$ for each value of $\theta_{e}$ (also true for the wet-bulb potential temperature $\theta_{w}$ ), so the difference between the air temperature and the lifted surface parcel allows an estimate of the surface-based lifted index (Hales and Doswell

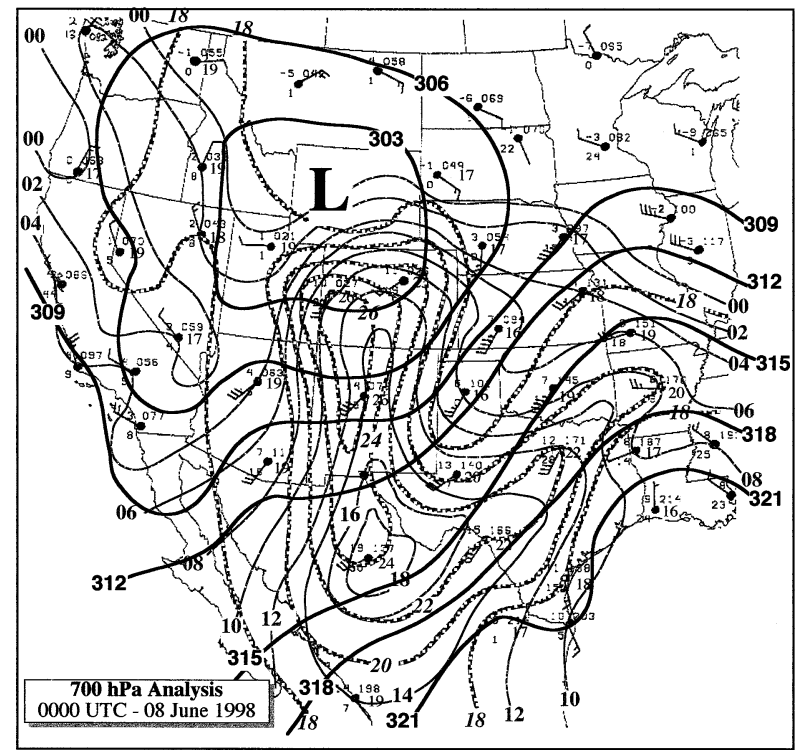

FIG. 6. The 700-hPa analysis as in Fig. 2 but for 0000 UTC 8 Jun 1998.

1982). Figure $11 \mathrm{~b}$ shows that surface parcels were stable over much of the Texas Panhandle, whereas a narrow tongue of considerable instability was present in southeastern New Mexico. A strong gradient of instability was present between the stable surface air in the Texas

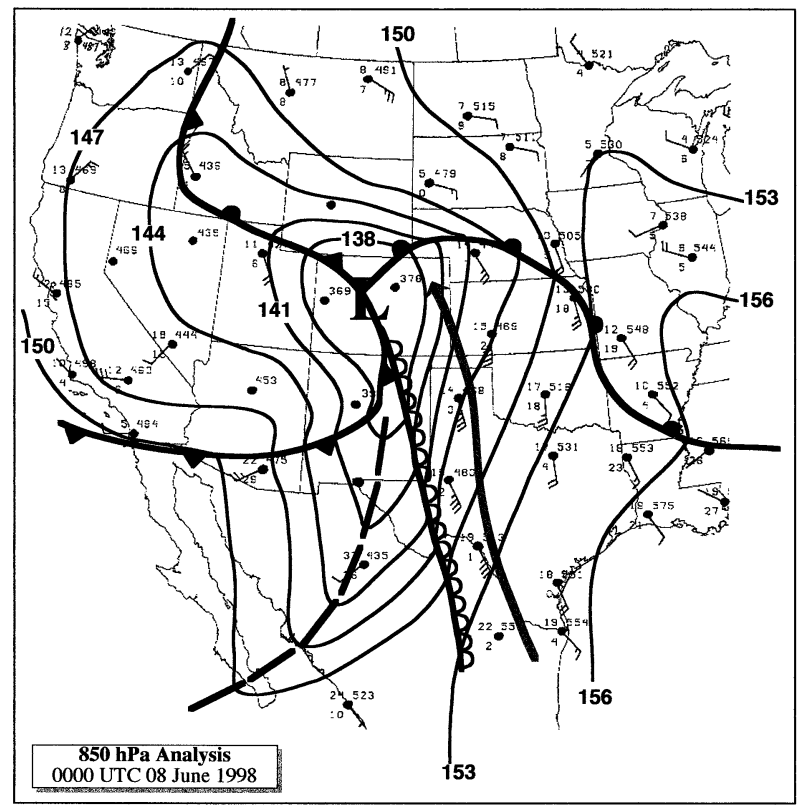

FIG. 7. Analysis of features at $850 \mathrm{hPa}$ at 0000 UTC 8 Jun 1998 , showing isohypses (heavy solid lines, contoured at 3-dam intervals). The scalloped line denotes the dryline, the dashed line denotes a geopotential trough, and frontal symbols are conventional. A heavy gray line with an arrowhead denotes the low-level jet stream axis. Station plots show temperature $\left({ }^{\circ} \mathrm{C}\right)$ in the upper left, dewpoint depression $\left({ }^{\circ} \mathrm{C}\right)$ in the lower left, and geopotential height (dam) in the upper right. 


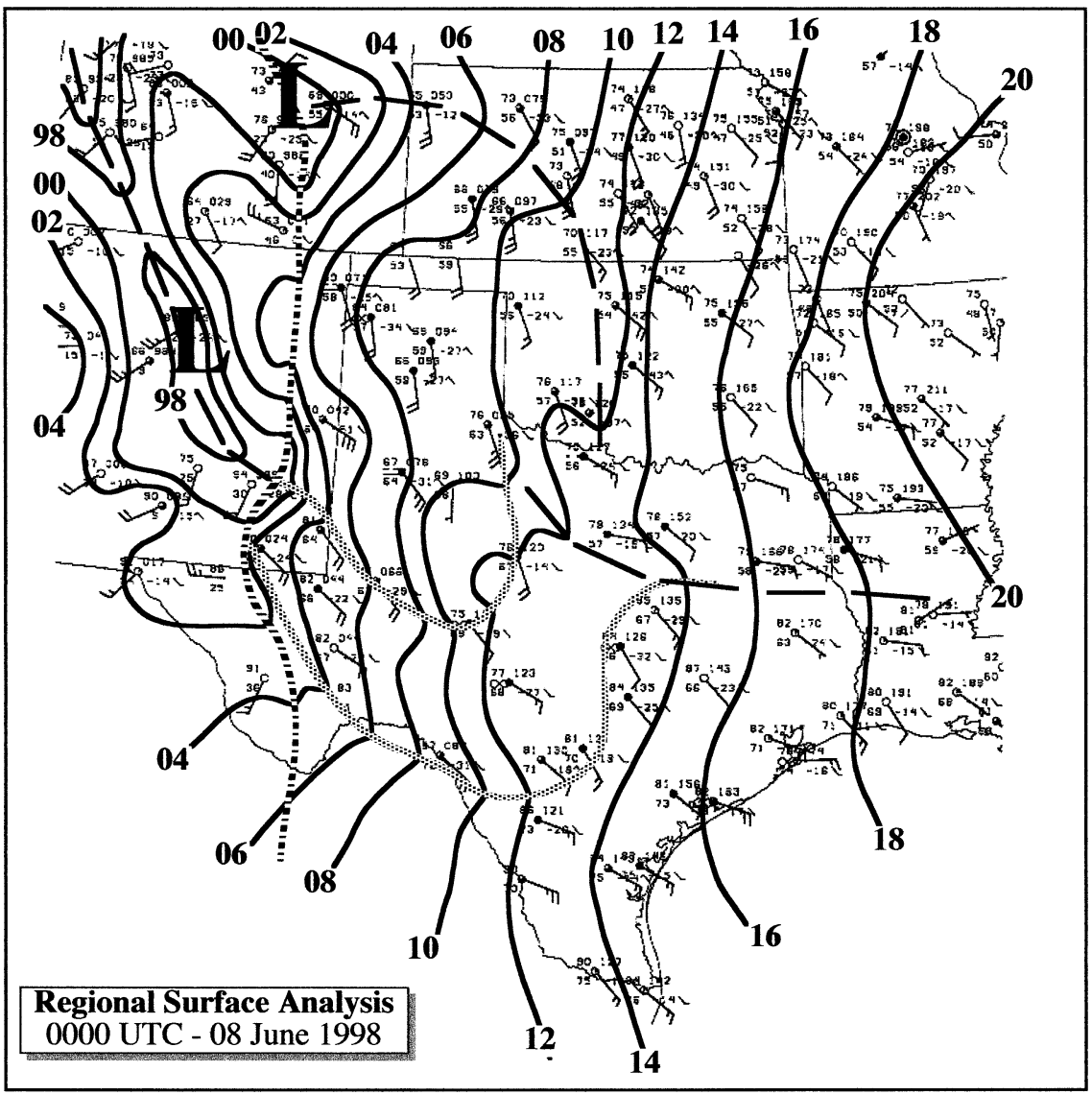

FIG. 8. Regional surface features at 0000 UTC 8 Jun 1998, showing surface isobars (solid lines, contoured at 2-hPa interval, labels only show the last two digits); the hatched line denotes the dryline, stippled lines denote thermal boundaries, and dashed lines denote troughs.

Panhandle and the unstable surface air in southeastern New Mexico, which can be described as a "boundary" between the two different air masses. ${ }^{4}$ Continuing cloudiness in western Texas was reducing the insolation available to warm the near-surface temperatures, in comparison with those in southeastern New Mexico. Figure 11 indicates that the southernmost supercell apparently developed near the dryline, within the tongue of warm temperatures associated with the clearing skies in southeastern New Mexico.

As shown in the Weather Surveillance Radar-1988 Doppler (WSR-88D) vertical wind profile from the Cannon Air Force Base, New Mexico, radar (Fig. 12) at this time, the threat area had a wind profile with considerable vertical wind shear, including notable veering in the layer just above the surface. It is well known in operational meteorology that such a wind profile is fa-

\footnotetext{
${ }^{4}$ The convention for indicating such a boundary as a line on a weather map is often problematic (Sanders and Doswell 1995). In actual practice, the ability to describe and to locate such a boundary is limited by the data resolution. The detailed surface maps shown here do not attempt to locate the boundary as a line but rather show subjective contours based on the available data.
}

vorable for supercells and possible tornadoes (Moller et al. 1994; Moller 2001).

A comparison between the 0000 UTC soundings at Amarillo (AMA) and Midland (MAF), Texas, is also revealing (Fig. 13). The absence of a sounding in eastern New Mexico unfortunately precludes knowing exactly what the surface-based instability was ahead of the thunderstorms that developed there on that afternoon. The Amarillo sounding was within the cool, cloudy air mass left behind in the wake of the early developing thunderstorms, whereas the Midland sounding was within a relatively warm, moist air mass (cf. Fig. 8), although it was not as warm as in southeastern New Mexico. The AMA sounding was about $5^{\circ} \mathrm{C}$ colder than the MAF sounding from the surface to about $600 \mathrm{hPa}$, thereby providing an estimate of the amount of cooling and the depth of the cool pool. From the surface values of temperature and dewpoint reported in each sounding, the 0000 UTC surface value of $\theta_{w}$ at AMA was about $20^{\circ} \mathrm{C}$, whereas that at MAF was roughly $23.5^{\circ} \mathrm{C}$. The sounding-derived values for the lifted index at AMA and MAF were -1 and -6 , respectively. In southeastern New Mexico, in the narrow band of warm, moist air, surface 

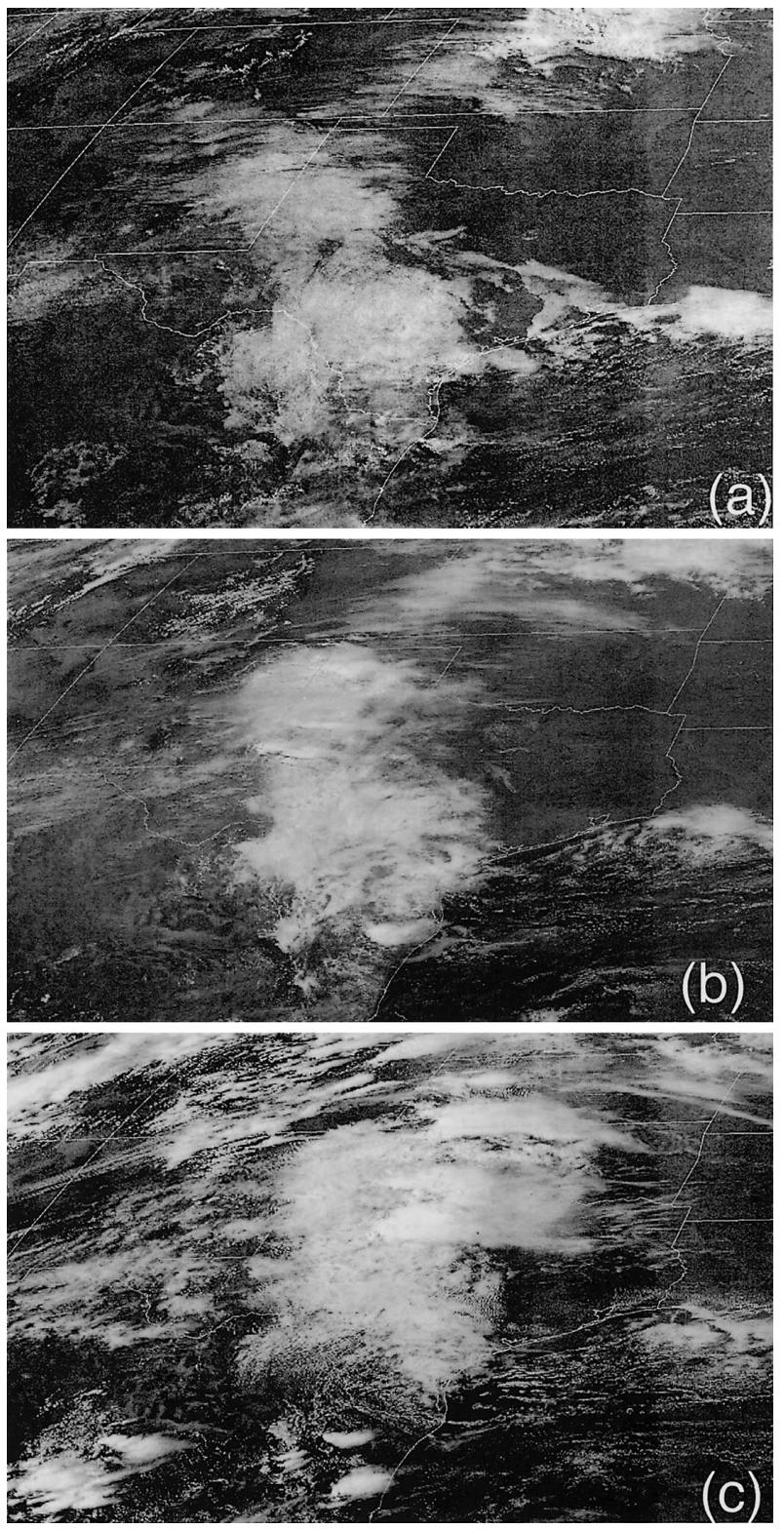

FIG. 9. Visible satellite images on 7 Jun 1998 at (a) 1402, (b) 1702, and (c) 2115 UTC.

values of $\theta_{w}$ were as high as $25^{\circ} \mathrm{C}$ at 2300 UTC (not shown). Although there apparently is a small amount of CAPE associated with the surface parcel in the AMA sounding $\left(\sim 500 \mathrm{~J} \mathrm{~kg}^{-1}\right)$, there is considerable convective inhibition (CIN) associated with that parcel's ascent curve $\left(\sim 200 \mathrm{~J} \mathrm{~kg}^{-1}\right)$, making it unlikely that the small amount of CAPE could easily be realized. On the other hand, considerable CAPE $\left(\sim 2500 \mathrm{~J} \mathrm{~kg}^{-1}\right)$ is found in the surface parcel for the MAF sounding, with little or no CIN. ${ }^{5}$ Thus, an analysis of soundings based on the

${ }^{5}$ Observe that as $\theta_{w}$ or $\theta_{e}$ increases, CAPE increases and CIN decreases, all other factors being equal.

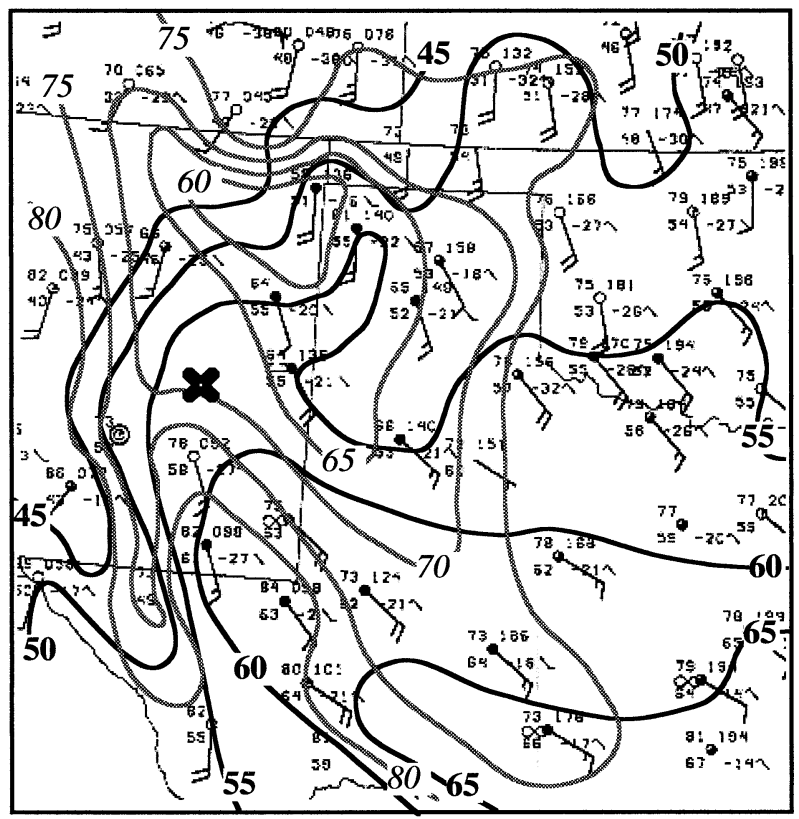

\section{UTC - 07 June 1998}

FIG. 10. Analysis of surface temperature (stippled lines, ${ }^{\circ} \mathrm{F}$ ) and dewpoint (solid lines, ${ }^{\circ} \mathrm{F}$ ) for 1800 UTC 7 Jun 1998. The approximate location at which the southernmost supercell developed (between 2100 and 2200 UTC) is indicated by the bold X.

surface parcels from these two locations gives very different indications of the surface-based instability, as confirmed in Fig. 13.

As already noted, despite the absence of a sounding in the specific area of interest, surface observations can be used to estimate the structure and evolution of parameters such as the lifted index, via the structure and evolution of surface $\theta_{e}$. As Fig. 14 shows at 0000 UTC, the estimates for the lifted index are not too different from those observed directly in the soundings (cf. Fig. 13). For a surface $\theta_{e}$ value exceeding $360 \mathrm{~K}$, this corresponds to peak lifted index values of around -7 to -8 . The boundary separating the unstable (negative lifted index) from the stable (positive lifted index) air masses was not moving very rapidly, although Fig. 14 shows that the impinging dryline has stabilized the surface air considerably to its west (cf. Fig. 11b).

By 0015 UTC, two of the three initial thunderstorm areas remained active; one along the KansasOklahoma border and the other moving through north Texas (Fig. 15a). The latter exhibited an "enhancedV' infrared satellite image signature (McCann 1983), but there was no reported severe weather with this storm. However, another major new thunderstorm area had developed, with its active convection at the upstream end of its large anvil in eastern New Mexico, just west of the Texas border. An enhanced-V sig- 


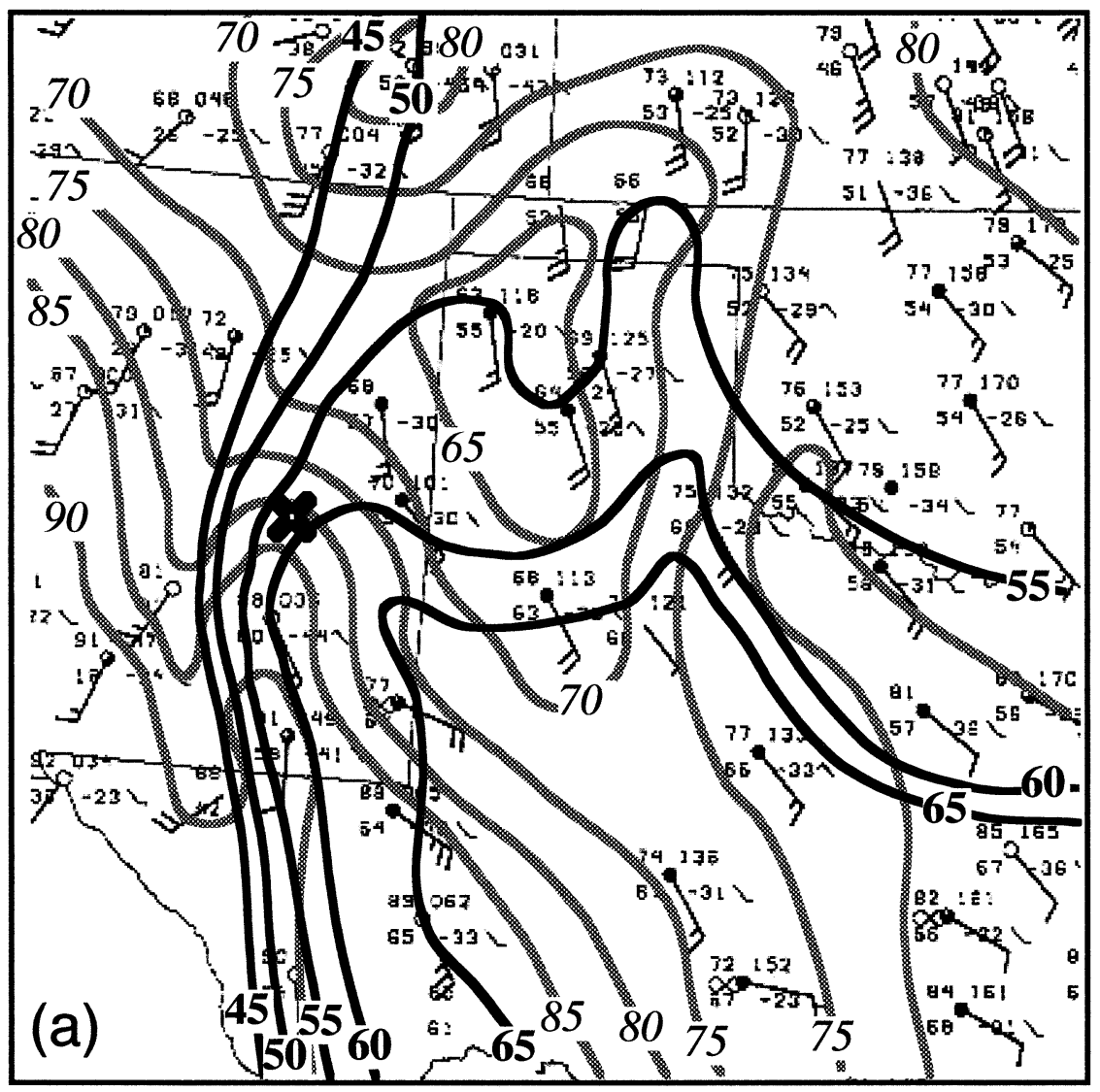

\section{UTC - 07 June 1998}

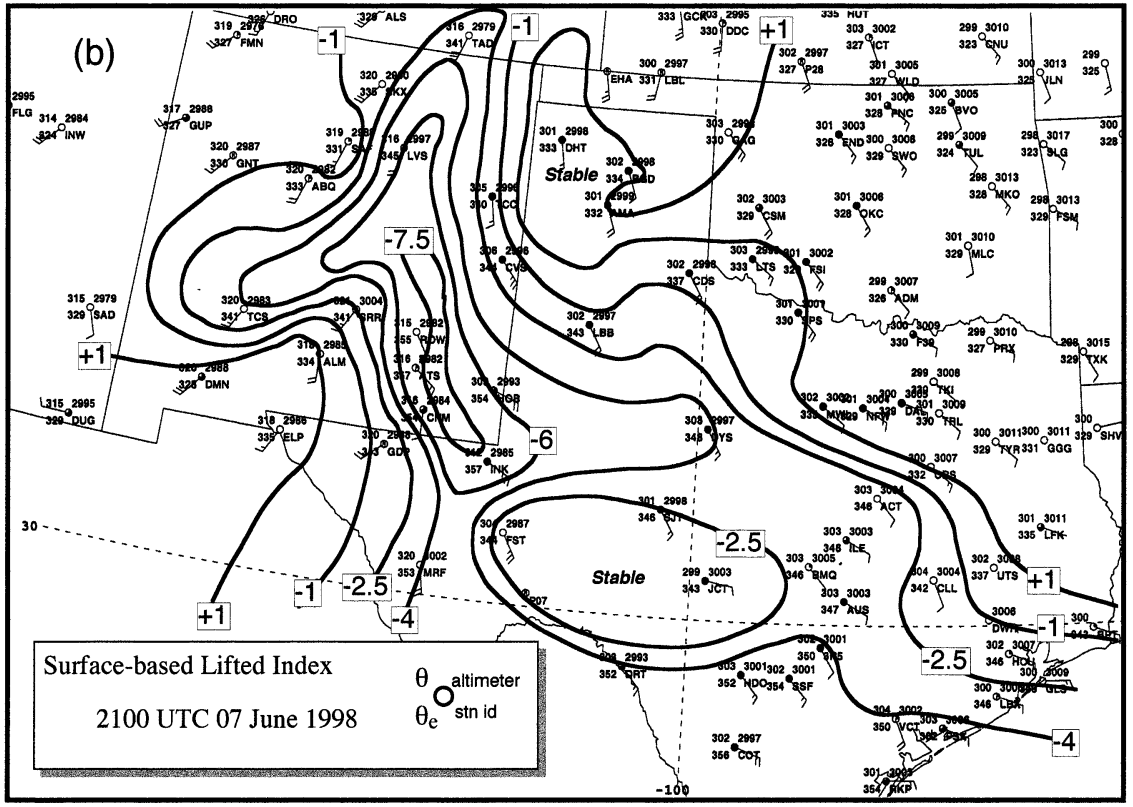

FIG. 11. (a) Surface analysis as in Fig. 10 but for 2100 UTC 7 Jun 1998; (b) 2100 UTC estimated lifted index $\left({ }^{\circ} \mathrm{C}\right)$ formed by subtracting the 0000 UTC ( 8 Jun 1998) temperature at $500 \mathrm{hPa}$ (Fig. $5)$ from the $500-\mathrm{hPa}$ lifted parcel temperature derived from the surface $\theta_{e}\left(\right.$ or $\left.\theta_{w}\right)$. Note the irregular contour interval, reflecting the estimation process. 


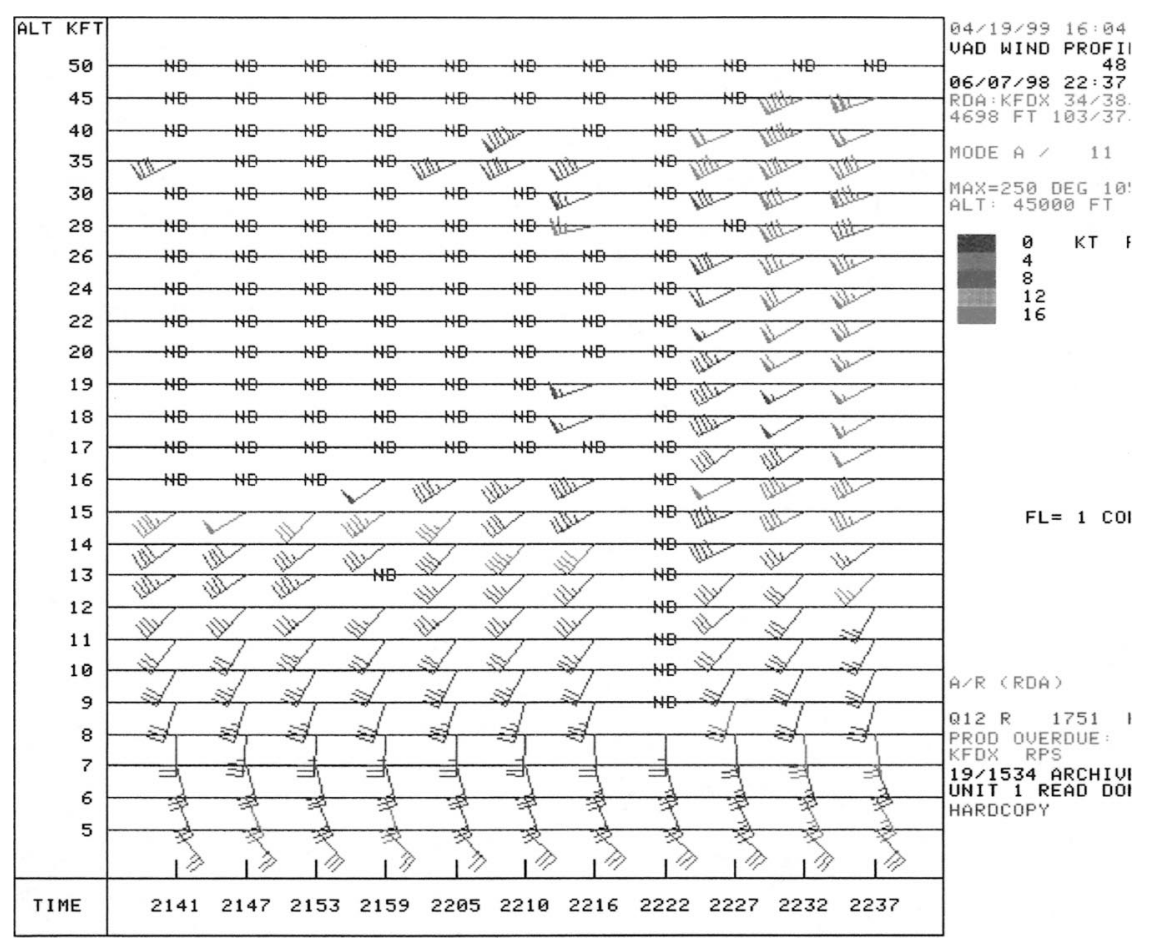

FIG. 12. Time section of vertical wind profile from the Cannon Air Force Base, NM, WSR$88 \mathrm{D}$, with time (UTC) indicated at the bottom, increasing to the right. Heights $\left(10^{3} \mathrm{ft}\right)$ are shown on the left. Wind barbs follow the National Weather Service operational convention (kt); ND indicates no data.

nature was also evident with the southernmost storm in this complex. These new thunderstorms had developed near the surface dryline around 2200 UTC (not shown) on the high plains of eastern New Mexico, west of Clovis. Recall the surface analysis (cf. Fig. 8) showing that the thunderstorms at 0000 UTC had already moved ahead of the surface position of the eastward-advancing dryline. Thus, they were in the narrowing gap between the dryline and the nearly stationary pool of cold, cloudy air left in the wake of the thunderstorms that developed in the late morning. As shown in Fig. 16a, at 2302 UTC, the thunderstorms were in relatively clear air but were approaching a region where some wavelike "billow" clouds could be seen extending from beneath the extensive cloud cover of western Texas. Scofield and Purdom (1986) and Weaver et al. (1994) have shown that such clouds indicate stable low-level air. Their western edge might therefore be viewed as an estimate of the location of the boundary between the stable and unstable surface air masses within the overall transition zone. Whereas the storms were west of this apparent boundary at 2302 UTC, by 0015 UTC 8 June (Fig. 16b) the surviving severe thunderstorm clearly had moved well across this apparent boundary.

Gaps in the low-level cloud bands permitted some modification of the surface temperatures by insolation, but the complete overcast just inside the Texas border meant that by the time the storm moved well into Texas it would be moving into a region of increasing static stability, which is confirmed by Fig. 14. By 0200 UTC, the thunderstorm that developed on the high plains of New Mexico was obviously moving across a region of surface air with decreasing instability and increasing CIN and so was unlikely to be lifted to its level of free convection. Infrared satellite imagery (at 0202 UTC 8 June; Fig. 15b) shows that this storm continued to exhibit an enhanced- $\mathrm{V}$ signature. The storm in northern Texas that earlier had also shown a similar signature was apparently decreasing in intensity; that is, the signature was no longer present. It can be seen from the 0300 UTC surface analysis (Fig. 17) that the western boundary of the cool pool was not moving eastward with the storm.

It seems that the persistence of a mesoscale area of cloudiness and outflow inhibited the destabilization at the surface ahead of the persistent supercell. Next, we need to consider what happened on the storm scale to see how this mesoscale feature apparently influenced the weather.

\section{The evolution of the convection}

The National Weather Service's operational network of WSR-88Ds provides a reasonably detailed picture of 


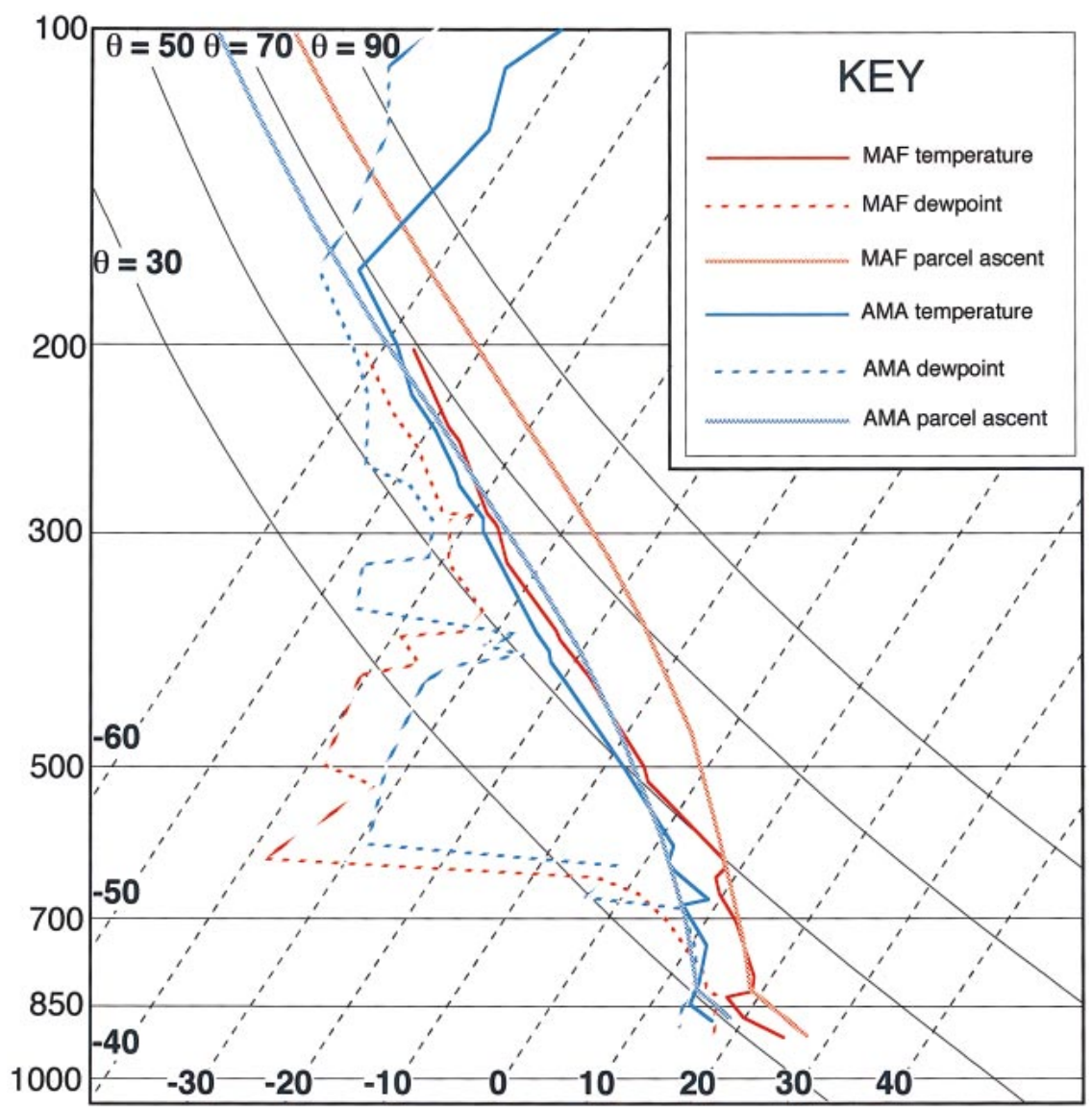

FIG. 13. Skew $T-\log p$ plots of Amarillo, TX (AMA; in blue), and Midland, TX (MAF; in red), soundings at 0000 UTC 8 Jun 1998; lifted parcel ascent curves shown include the virtual temperature correction. Isobars (thin solid lines) are labeled in hectopascals, and isotherms (thin dashed lines) and isentropes (curved thin solid lines) are both labeled in degrees Celsius.

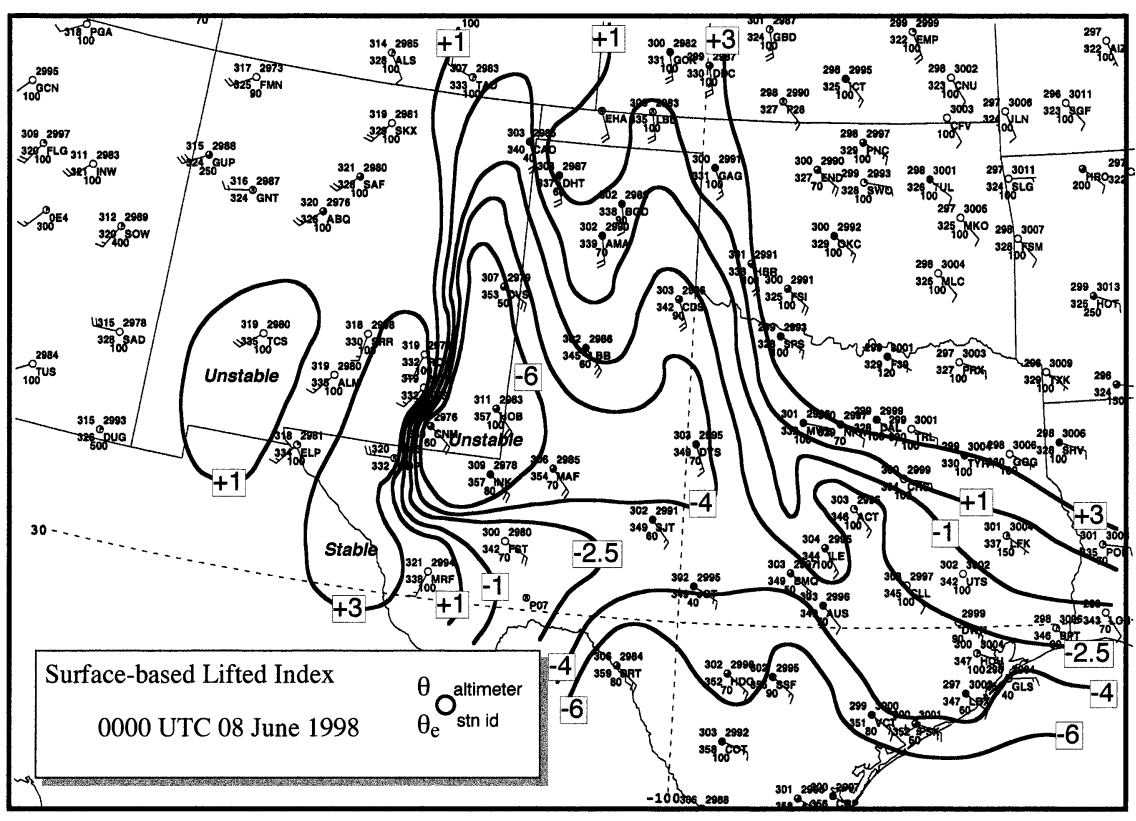

FIG. 14. Analysis of estimated lifted index as in Fig. 11b but at 0000 UTC 8 Jun 1998. 

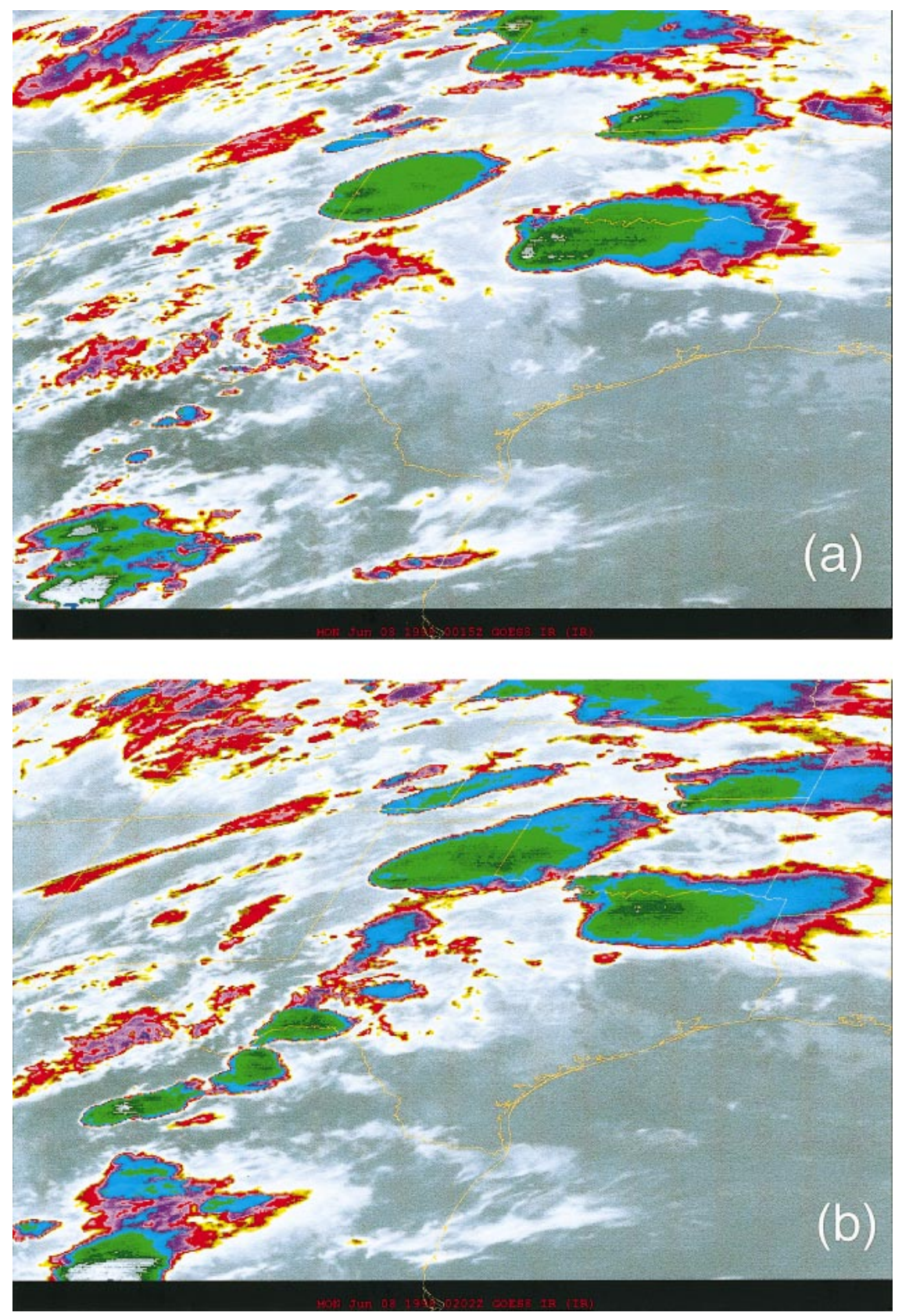

FIG. 15. False color-enhanced infrared satellite image on 8 Jun 1998 at (a) 0015 and (b) 0202 UTC. Dark greens and grays indicate the coldest cloud-top infrared temperatures.

the character of the convection on this day. ${ }^{6}$ As shown in Fig. 18, the nearest WSR-88D [at Cannon Air Force Base (KFDX)] is relatively close to the events in Clovis, New Mexico, although that in Lubbock, Texas (KLBB),

\footnotetext{
${ }^{6}$ Although the presence of scientific storm chasers in the area on this day provides research datasets that could give additional detail for diagnosis of this case, we have not incorporated such data. Our intent is not to attempt a detailed analysis using all available data but rather to suggest what operational forecasters would be able to do with their routinely available observations.
}

is distant from the storms. At 2205 UTC (Fig. 19a), there were two strong storms in eastern New Mexico, as depicted by the KFDX radar, the northernmost of which was more mature and displayed an operational algorithm-detectable mesocyclone (Zrnić et al. 1985). By 2232 UTC (not shown), both storms had mesocyclone signatures, but at 2323 UTC (Fig. 19b) the northernmost storm was beginning to decay while the southernmost storm was approaching Clovis. The presence of persistent WSR-88D algorithm-detectable mesocy- 

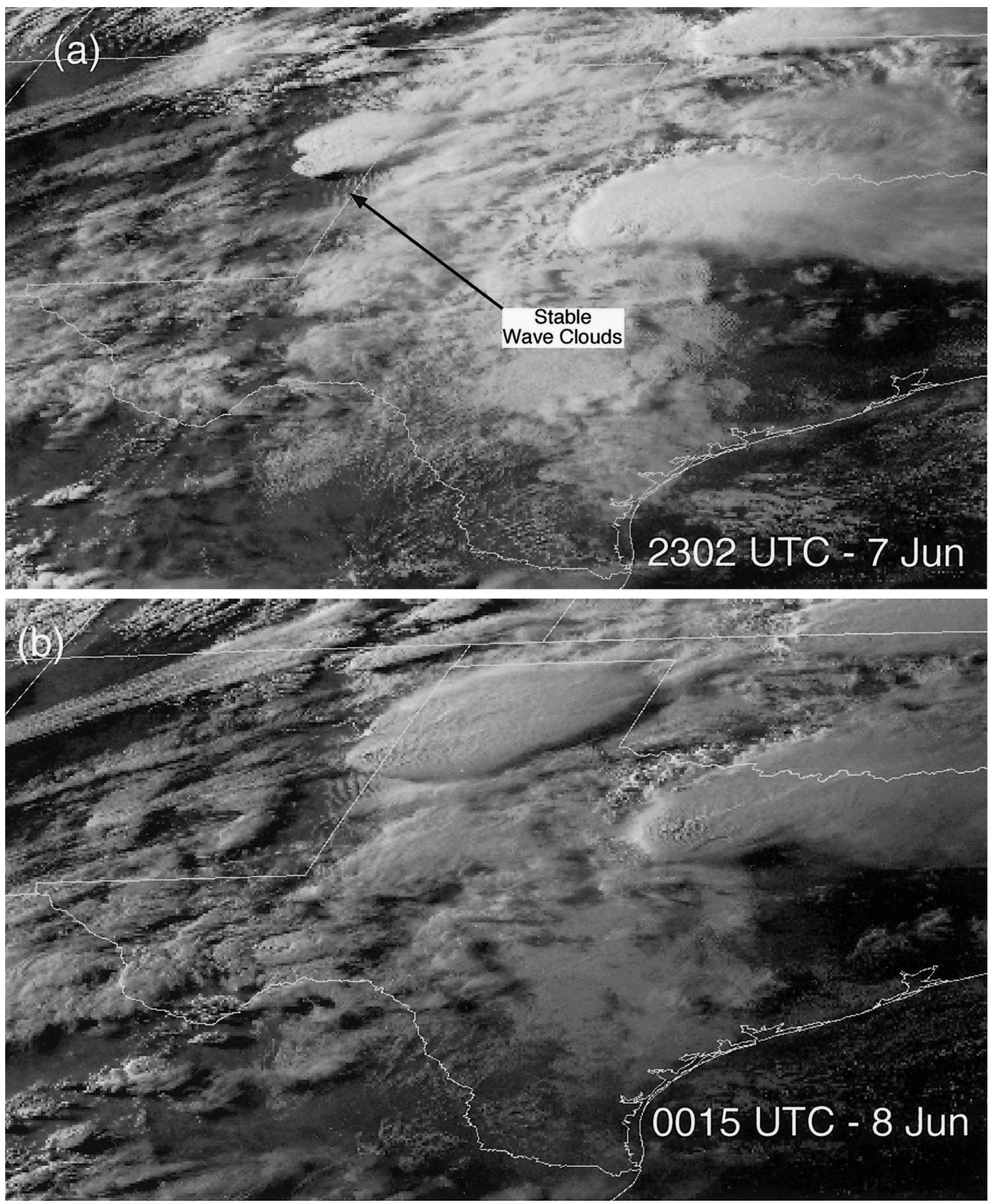

FIG. 16. Visible satellite images at (a) 2302 UTC 7 Jun 1998 and (b) 0015 UTC 8 Jun 1998.

clones and the low-level radar morphology make it pretty clear that both storms were supercells; see Doswell and Burgess (1993) for a discussion of the observable characteristics associated with supercells. The WSR$88 \mathrm{D}$ image of the southern storm at 0017 UTC is notable for its obvious supercellular morphology (Fig. 19c).

The northern storm continued its decline, but the southern storm maintained its supercell characteristics across the northern parts of Clovis and on into Texas. At 0037 UTC, the KLBB radar revealed a bounded weak echo region (Fig. 19d), indicative of continuing supercell characteristics for the storm. Further evidence for the continuing supercellular character can be found in the low-level reflectivity (Fig. 20a) and radial velocity 


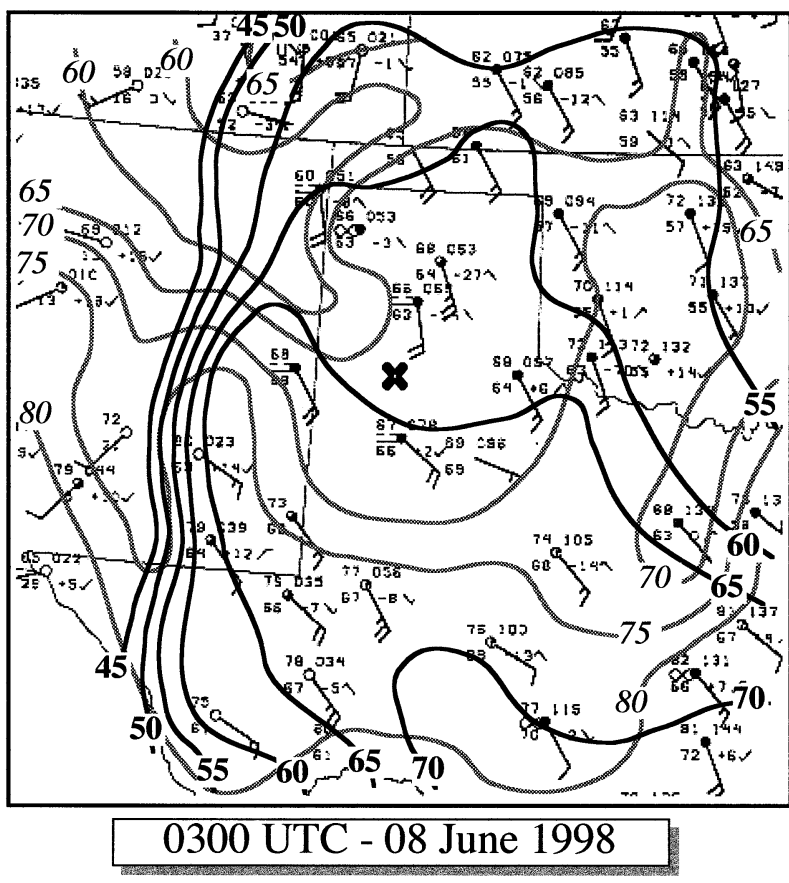

FIG. 17. Surface analysis as in Fig. 10 but for 0300 UTC, and the $\mathrm{X}$ marks the approximate location of the supercell storm.

structure (Fig. 20b). An hour later, at 0136 UTC, the storm maintained its radar-observed supercell characteristics (not shown), and this was still so at 0237 UTC (Figs. 20c,d). After 0237 UTC, the storm began gradually to decay.

The path of this storm across Curry County in New Mexico, as well as Parmer, Castro, and Swisher Counties in Texas, resulted in several reports of severe weather (Fig. 21), mostly large hail [up to 4.5 in. $(11 \mathrm{~cm})$ in diameter in Castro County]. Of note is that the tornadoes associated with this supercell occurred in Curry County and just inside the Texas border, in extreme western Parmer County. In spite of having supercell characteristics for many hours, the storm became tornadic only briefly, during the time when it was interacting with the boundary and shortly thereafter, but went on to produce large hail for several hours after its tornadic phase.

\section{Discussion and conclusions}

The surface analyses show that, after forming near the dryline but during its tornadic phase, the supercell was near the apex of a ridge of warm, moist air approaching the area from the south. As the supercell produced its tornadoes, however, it was moving eastward away from the axis of this ridge of warm and moist air and was interacting with the western boundary of the cloudy, relatively cool air left behind in the wake of the deep convection that had developed early in Texas. Relatively soon after moving east of the boundary, the

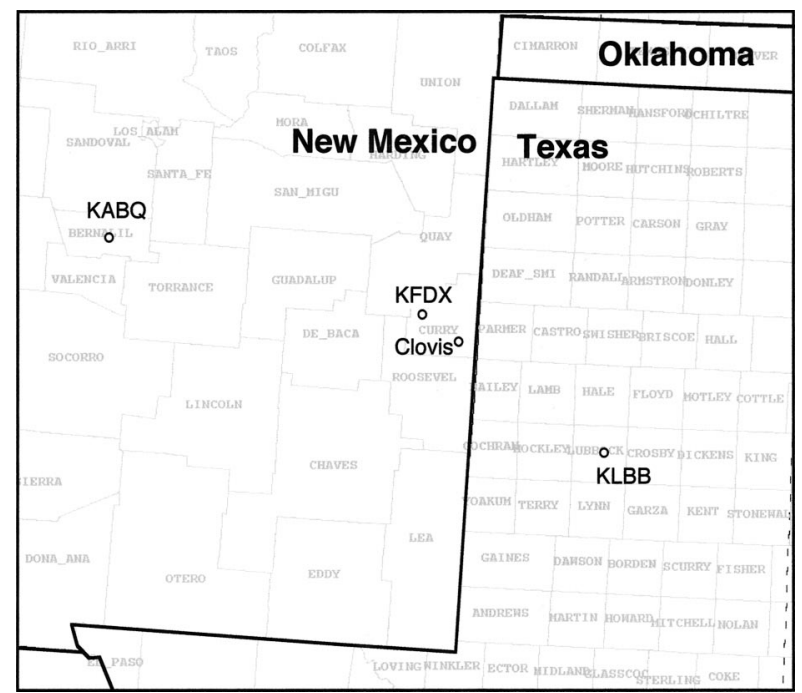

FIG. 18. Map showing the location of Albuquerque, NM (KABQ); Cannon Air Force Base, NM (KFDX); and Lubbock, TX (KLBB), WSR-88Ds, as well as Clovis, NM, superimposed on the county boundaries (and names) in gray.

storm apparently became an "elevated" supercell storm. ${ }^{7}$

Rasmussen et al. (2000) document that storms encountering old outflow boundaries sometimes may have enhanced tornadic potential. Their work tends to support earlier observations by Maddox et al. (1980), which show that storms moving across a strong stability boundary are most likely to produce tornadoes only during that interaction with the boundary (see also Imy et al. 1992), with tornado production becoming less likely as the storms move deeper into the stable surface air mass. Maddox et al. suggest that storms moving roughly parallel to strong stability boundaries are more likely to maintain their tornado potential than storms moving roughly perpendicular to the boundary and into the markedly less unstable air mass. This tendency obviously depends on the stability within the cool air. If some nonnegligible CAPE remains for surface parcels within the cool air, storms moving into that air mass might continue to be tornadic. For our case of 7-8 June 1998, the pool of cloudy air the supercell encountered was mostly cool and either only marginally unstable or actually stable, with unstable surface $\theta_{w}$ values as a result of modification by solar heating only in eastern New Mexico and extreme west Texas.

The early deep convection produced outflow and continuing cloudiness that maintained the cool temperatures all afternoon. Therefore, only a relatively narrow region of surface-based moist, substantially unstable air was present within the transition zone that separated the

\footnotetext{
7 According to Colman (1990), an "elevated" storm is one in which the parcels participating in the convective updraft are not originating at or very near the surface. It is typically associated with deep convection above a surface-based stable layer.
} 

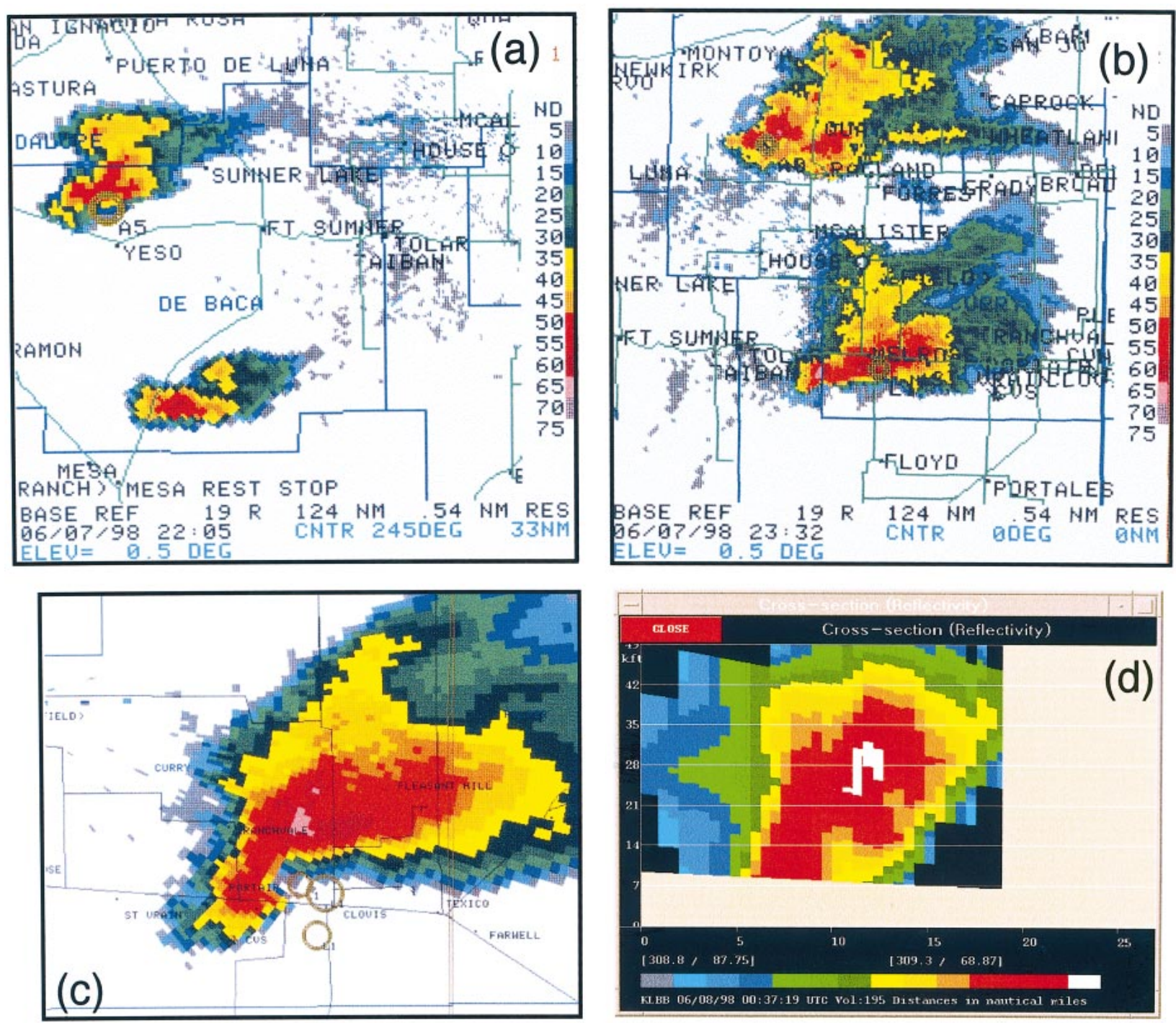

FIG. 19. WSR-88D radar depiction from KFDX, showing $0.5^{\circ}$ elevation scan reflectivity (dBZ) at (a) 2205 and (b) 2332 UTC 7 Jun 1998. Yellow circles depict algorithm-detected mesocyclone signatures [see Zrnić et al. (1985) for details about the algorithm]. (c) Close-up view of the southern supercell at 0017 UTC 8 Jun 1998. (d) A WSR-88D cross section of the supercell at 0037 UTC, as seen on the KLBB radar, showing reflectivity structure.

warm, unstable air mass ahead of the approaching dryline to the west from the mesoscale cold pool to the east. It was within this narrow region of high instability that the supercell developed, becoming tornadic as it began to interact with the western boundary of the cool air mass. The development of the southern supercell storm might have contributed to the relatively early demise of the northern supercell, perhaps by intercepting its inflow of low-level, high- $\theta_{w}$ air or by pushing its outflow into the inflow of the northern storm. Once the single remaining supercell moved across the fairly narrow zone in which conditions were most favorable for tornadoes in the vicinity of the western boundary of the cool air, it encountered increasingly cool, less unstable air at the surface and tornado production ceased, more or less as described by Maddox et al. (1980). However, it appears that the environment remained favorable for supercells above the surface-based, mesoscale cool pool, so the now-elevated supercell continued to produce copious amounts of hail, with diameters exceeding $10 \mathrm{~cm}$. Note that the surface-based cool air also apparently limited the strong surface wind gust potential for this storm; the only reported severe wind gust occurred in southeastern Curry County in New Mexico, before the storm crossed the boundary. Any strong downdrafts created by the supercell were apparently unable to penetrate to the surface through the strongly stable mesoscale cool pool.

Although it is not possible to know what might have happened had the early storms not developed in the 

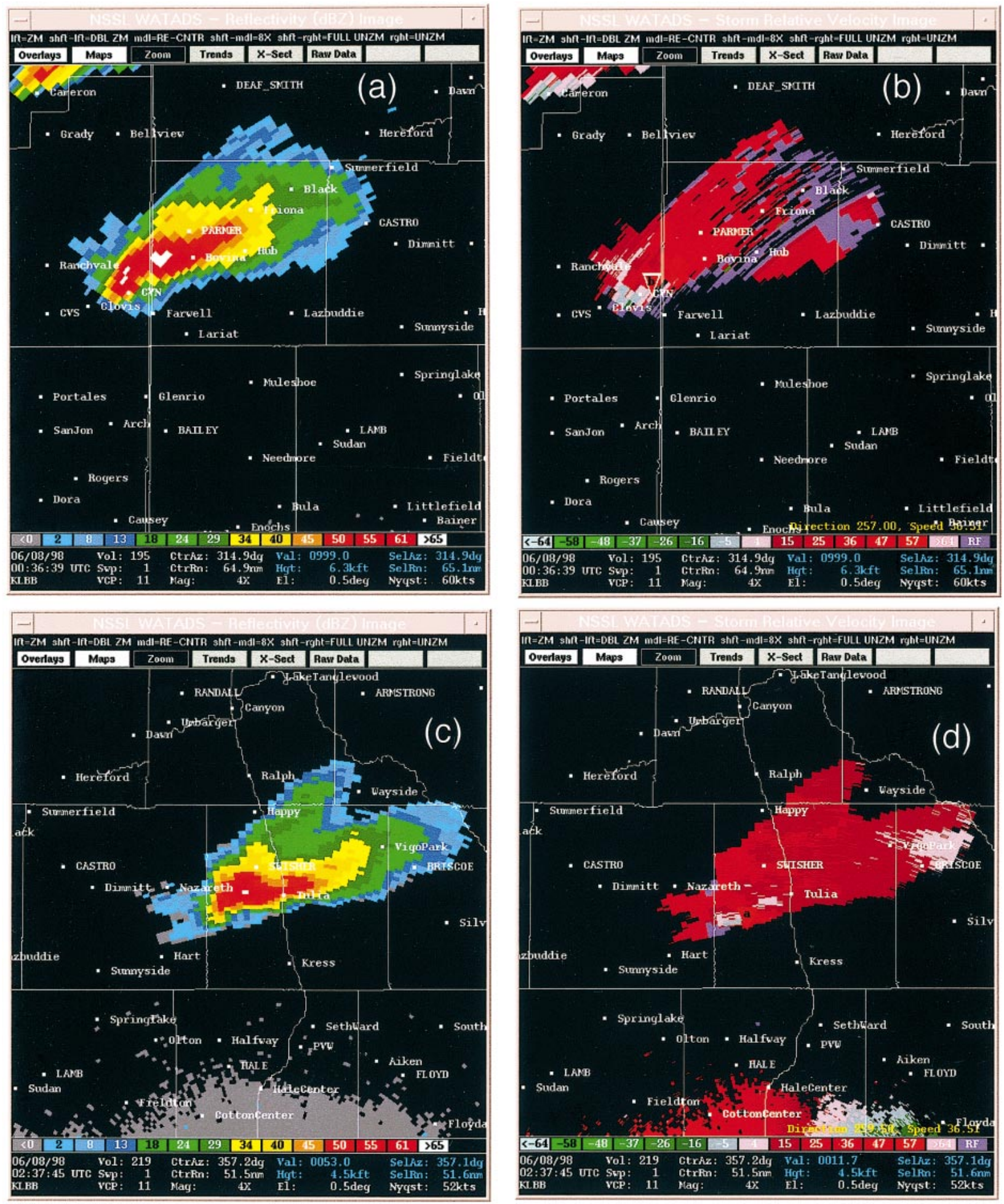

FIG. 20. KLBB view of (a) reflectivity (dBZ) and (b) storm-relative radial velocity at $0036 \mathrm{UTC} 8 \mathrm{Jun} 1998$, at $0.5^{\circ}$ tilt; (c) reflectivity (dBZ) and (d) storm-relative radial velocity at 0237 UTC 8 Jun 1998 , at $0.5^{\circ}$ tilt. 


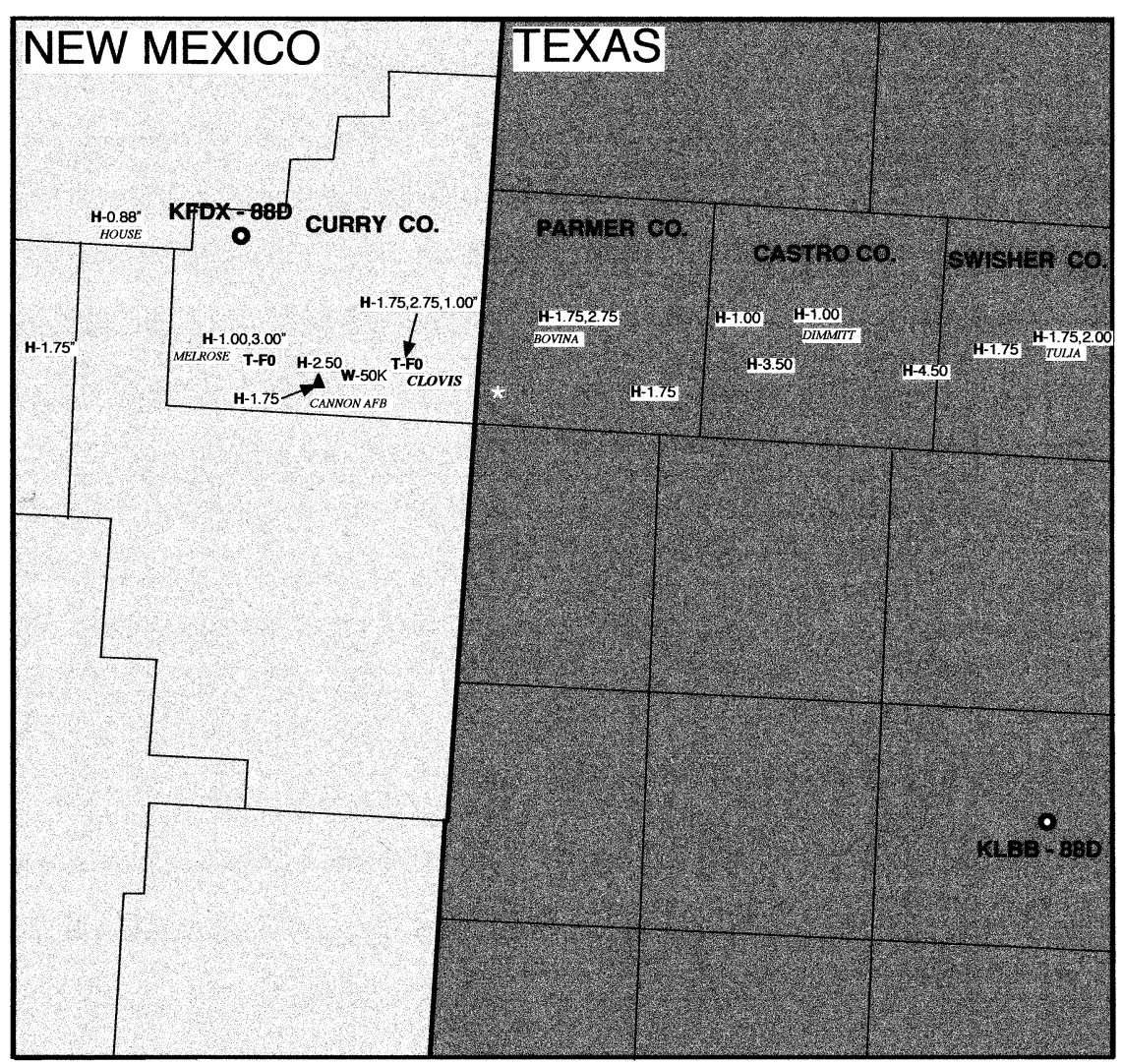

FIG. 21. Map of the reported severe weather, with $\mathrm{H}$ denoting a hail report (diameter given as reported, in.), W denoting a wind report (speed given as reported, kt), and $\mathrm{T}$ denoting a tornado (F scale rating given). A third, brief tornado (not included in the official log of severe weather) was observed by some storm chasers (P. Markowski 2001, personal communication) just east of Farwell, TX, at 0042 UTC. This location is shown by an asterisk.

Texas Panhandle, it certainly appears that a situation with at least some potential for significantly tornadic supercells was limited by the mesoscale cool pool maintained by the early storms. In this case, the cool pool did not prevent the supercell (which became elevated after encountering the cool pool) from continuing to produce large hail for several hours, but its behavior is consistent with a negligible tornado potential once the storm moved well beyond the transition zone between the narrow band of unstable surface air just ahead of the dryline and the stability deep within the cool pool.

Forecasters with hazardous-weather warning responsibilities should maintain vigilant diagnostic procedures to be aware of the changing mesoscale circumstances. In this case, even at its lowest elevation angle $\left(0.5^{\circ}\right)$, the KLBB radar beam overshot the cool pool for most, if not all, of the storm's passage across it. Therefore, the supercellular appearance of the storm on the WSR$88 \mathrm{D}$ continued to suggest the possibility of tornadoes well after crossing the boundary. One of the authors (DVB) was working in the Lubbock, Texas, National Weather Service office that evening. Tornado warnings for the storm were maintained as it moved across all of Parmer County, even though spotters did not report any tornadoes. At that point, however, the office staff realized the elevated character of the storm and dropped the tornado warnings while continuing severe thunderstorm warnings. The challenge during the evening had been to recognize the nature of the boundary the storm had crossed and the change in stability associated with it. The characteristics of the mesoscale cool pool were difficult to diagnose during the ongoing warning activities.

In becoming an elevated supercell, the storm's inflow was forced to override the cool air, but the mesoscale cool pool probably reduced the probability of tornadoes. There were numerous storm chasers following this storm for most of its life, making it unlikely that any tornadoes would have gone unobserved. One of the authors (CAD) was among those who chased this storm and observed a classic rear-flank downdraft "clear slot" (Moller et al. 1974), but there was no lowered-base "wall cloud" structure during the passage of the storm across eastern Parmer and Castro Counties in Texas. Although this by itself is not an unambiguous indication of the lack of surface-based inflow, it is noteworthy that the storm did have a wall cloud in the vicinity of Clovis. The convective towers of the storm were not visible by 
the time the storm was well into Texas, owing to a "stratiform" overcast, and the storm appeared only as a darkening of the cloud base, with the clear slot being the only visual evidence of the storm's supercell character.

Forecasters having the responsibility for issuing warnings would need to monitor carefully the changing mesoscale environment for this storm as it moved into Texas. The physical limitations of the WSR-88D radars (notably the "horizon problem" associated with the beam overshooting low-level features) to detect the important near-surface characteristics of this storm make this an especially challenging warning situation. Moreover, surface data alone cannot be used to measure reliably the depth or stability of a cold outflow. The 0000 UTC soundings at MAF and AMA do reveal the character of the air masses well, but 0000 UTC sounding data arrived well into what had been a challenging situation for issuing warnings. A well-trained storm spotter (Doswell et al. 1999) might have recognized the apparent elevated nature of the storm and been able to inform the forecasters of the situation. Storm-spotter input is most helpful when (a) the forecaster has maintained "situation awareness" through continuous mesoscale diagnosis, (b) forecasters are knowledgeable about the potential for severe weather revealed by the storm (in this case, the elevated character of the supercell), and (c) storm spotters are trained well in recognizing salient features of the storms they are watching.

Despite the difficulties in knowing definitely what might have happened in the absence of the early convective storms, the observed evolution of the storm is at least consistent with the proposed inhibiting character of this particular mesoscale process. In fact, the behavior of the storm is consistent with the observations of Maddox et al. (1980). The tornadoes produced by the storm were not significant in intensity, duration, or impact. Had the storm gone on to produce a family of strong, long-lived tornadoes, it is possible that at least one community in the storm's path across Texas could have been struck and seriously damaged. On days such as 3 May 1999 in Oklahoma and Kansas, when tornado outbreaks occur with multiple supercells, each producing a series of tornadoes (some of which are of strong to violent intensity and may be long tracked), something quite different is happening on the mesoscale than on days such as this one, during which the supercells were isolated and the tornadoes were essentially brief and weak. It remains a challenge to be able to recognize these differences soon enough to influence forecasting and warning decisions.

Our experience indicates that the mesoscale factors that are an important component of hazardous-weather events might well be most effective at inhibiting hazardous weather (at least for rare events such as tornadoes). Forecasters strive constantly to reduce false alarms associated with nonevents wherein it appears that the situation has some potential to produce an event but that potential may not be realized. Given the relatively low "penalty" associated with a false alarm as compared with that when a tornado devastates a community without a tornado warning being issued, it takes particular care and some courage not to continue with tornado warnings for a persistently severe supercell storm.

Current scientific understanding of tornadoes and the existing routine observations generally do not make this an easy decision. We believe that when scientific studies focus mainly on events rather than on nonevents, it creates an asymmetry in the scientific literature that makes forecasting using available scientific concepts very challenging. For tornado warnings in particular, it is possible that event-only studies could eventually provide a reasonably comprehensive understanding of tornadogenesis, and the operational application of that understanding might be both straightforward in terms of what variables to look for in the diagnosis and practical in terms of permitting accurate decisions based on routinely available data. Such an understanding could make it clear why most situations involving supercells either fail to be tornadic or only produce brief, weak tornadoes. Until such a comprehensive understanding becomes available, however, we believe there is a continuing need for scientific studies of the "failure modes" (e.g., Trapp 1999) in situations that have some tornado potential so as to help to solve the forecasters' main challenge: to reduce false alarms. It is also likely that studies of tornadogenesis failure will be an important component in developing the hoped-for comprehensive understanding. When scientific studies ignore nonevents, they necessarily omit consideration of the most frequent type of weather evolution.

Acknowledgments. The authors appreciate the assistance provided by Loretta McKibben and Vikki Farmer (Cooperative Institute for Mesoscale Meteorological Studies) in creating figures. Rich Thompson (Storm Prediction Center), Roger Edwards (Storm Prediction Center), and Matt Wandishin (National Severe Storms Laboratory) provided valuable comments on an early version of the manuscript. Additional comments provided by Paul Markowski (The Pennsylvania State University), John Hart (Storm Prediction Center), and an anonymous reviewer improved the presentation. John Hart helpfully supplied us with some additional data.

\section{REFERENCES}

Agee, E. M., J. T. Snow, and P. R. Clare, 1976: Multiple vortex features in the tornado cyclone and the occurrence of tornado families. Mon. Wea. Rev., 104, 552-563.

Colman, B. R., 1990: Thunderstorms above frontal surfaces in environments without positive CAPE. Part I: A climatology. Mon. Wea. Rev., 118, 1103-1122.

Davies, J. M., C. A. Doswell III, D. W. Burgess, and J. F. Weaver, 1994: Some noteworthy aspects of the Hesston, Kansas, tornado family of 13 March 1990. Bull. Amer. Meteor. Soc., 75, 10071017.

Doswell, C. A., III, 1987: The distinction between large-scale and 
mesoscale contribution to severe convection: A case study example. Wea. Forecasting, 2, 3-16.

- and D. W. Burgess, 1993: Tornadoes and tornadic storms: A review of conceptual models. The Tornado: Its Structure, Dynamics, Hazards, and Prediction, Geophys. Monogr., No. 79, Amer. Geophys. Union, 161-172.

_, R. H. Johns, and S. J. Weiss, 1993: Tornado forecasting: A review. The Tornado: Its Structure, Dynamics, Hazards, and Prediction, Geophys. Monogr., No. 79, Amer. Geophys. Union, 557-571.

- A. R. Moller, and H. E. Brooks, 1999: Storm spotting and public awareness since the first tornado forecasts of 1948. Wea. Forecasting, 14, 544-557.

Forbes, G. S., 1981: On the reliability of hook echoes as tornado indicators. Mon. Wea. Rev., 109, 1457-1466.

Fujita, T. T., 1960: A detailed analysis of the Fargo tornadoes of June 20, 1957. U.S. Weather Bureau Res. Paper 42, 67 pp.

Hales, J. E., Jr., and C. A. Doswell III, 1982: High resolution diagnosis of instability using hourly surface parcel lifted temperatures. Preprints, 12th Conf. on Severe Local Storms, San Antonio, TX, Amer. Meteor. Soc., 75-78.

Imy, D. A., K. J. Pence, and C. A. Doswell III, 1992: On the need for volumetric radar data when issuing severe thunderstorm and tornado warnings. Natl. Wea. Dig., 17 (4), 2-17.

Jones, W. A., K. K. Keeter, and L. G. Lee, 1985: Some considerations for long-range radar evaluation of potentially tornadic thunderstorms. Preprints, 14th Conf. on Severe Local Storms, Indianapolis, IN, Amer. Meteor. Soc., 139-142.

Maddox, R. A., L. R. Hoxit, and C. F. Chappell, 1980: A study of tornadic thunderstorm interactions with thermal boundaries. Mon. Wea. Rev., 108, 322-336.

Magor, B. W., 1959: Meso-analysis: Some operational analysis techniques utilized in tornado forecasting. Bull. Amer. Meteor. Soc., 40, 499-511.
McCann, D. W., 1983: The enhanced-V: A satellite observable severe storm signature. Mon. Wea. Rev., 111, 887-894.

Moller, A. R., 2001: Severe local storms forecasting. Severe Convective Storms, Meteor. Monogr., No. 50, Amer. Meteor. Soc. 433-480.

-, C. Doswell, J. McGinley, S. Tegtmeier, and R. Zipser, 1974 Field observations of the Union City tornado in Oklahoma. Weatherwise, 27 (2), 68-79.

— - M. P. Foster, and G. R. Woodall, 1994: The operational recognition of supercell thunderstorm environments and storm structures. Wea. Forecasting, 9, 327-347.

Rasmussen, E. N., S. Richardson, J. M. Straka, P. M. Markowski, and D. O. Blanchard, 2000: The association of significant tornadoes with a baroclinic boundary on 2 June 1995. Mon. Wea. Rev., 128, 174-191

Rockwood, A. A., and R. A. Maddox, 1988: Mesoscale and synoptic scale interactions leading to intense convection: The case of 7 June 1982. Wea. Forecasting, 3, 51-68.

Sanders, F. P., and C. A. Doswell III, 1995: A case for detailed surface analysis. Bull. Amer. Meteor. Soc., 76, 505-521.

Scofield, R. A., and J. F. W. Purdom, 1986: The use of satellite data for mesoscale analyses and forecasting applications. Mesoscale Meteorology and Forecasting, P. S. Ray, Ed., Amer. Meteor. Soc., 118-150.

Trapp, R. J., 1999: Observations of nontornadic low-level mesocyclones and attendant tornadogenesis failure during VORTEX. Mon. Wea. Rev., 127, 1693-1705.

Weaver, J. F., J. F. W. Purdom, and E. J. Szoke, 1994: Some mesoscale aspects of the 6 June 1990 Limon, Colorado, tornado case. Wea. Forecasting, 9, 45-61.

Weisman, M. L., and J. B. Klemp, 1986: Characteristics of isolated convective storms. Mesoscale Meteorology and Forecasting, P. S. Ray, Ed., Amer. Meteor. Soc., 331-358.

Zrnić, D. S., D. W. Burgess, and L. D. Hennington, 1985: Automatic detection of mesocyclonic shear with Doppler radar. J. Atmos. Oceanic Technol., 2, 425-438. 